\title{
2 Home modeling after penile prosthesis implantation in the management of residual curvature in Peyronie's disease
}

\author{
Ignacio Moncada ${ }^{1} \cdot{\text { Pramod Krishnappa } \mathbb{D}^{2} \cdot \text { Julmar Ascencios }^{1} \cdot \text { Inigo Lopez }^{1} \cdot \text { Juan Ignacio Martinez Salamanca }}^{3}$
}

Received: 9 February 2020 / Revised: 24 May 2020 / Accepted: 29 June 2020

(c) The Author(s), under exclusive licence to Springer Nature Limited 2020

\begin{abstract}
The aim of this study was to study the clinical effectiveness of a structured home modeling (HM) protocol in Peyronie's disease (PD) patients who have residual curvature up to $45^{\circ}$ after inflatable penile prosthesis (PP) placement. A total of 92 patients with PD and coexistent refractory erectile dysfunction received inflatable PP. If residual curvature after manual modeling (MM) was more than $45^{\circ}$, incision-grafting was performed. If curvature was $<45^{\circ}$ after $\mathrm{MM}$, patients were instructed to perform HM daily for 6 months, after 4 weeks from PP implantation. The mean preoperative penile curvature was $39.4 \pm 5.7^{\circ}(30-60)$. Sixteen $(17.4 \%)$ patients required incision-grafting and the remaining $76(82.6 \%)$ patients followed $\mathrm{HM}$ protocol. The mean postoperative residual curvature after MM was $29.7 \pm 3.2^{\circ}(5-50)$. Sixty-five $(85.5 \%)$ patients who underwent $\mathrm{HM}$ had $10^{\circ}$ or less residual curvature after 3 months and $72(94.7 \%)$ patients had $10^{\circ}$ or less residual curvature after 6 months. Seventy (92.1\%) patients responded as satisfied or very satisfied on the questionnaire with the outcome after 6 months. HM of the penis over Inflatable PP may straighten the penis without the need for an additional surgical maneuver in vast majority of the PD patients having residual curvature of $<45^{\circ}$.
\end{abstract}

\section{Introduction}

Peyronie's disease (PD) is a connective tissue disorder which mainly affects the tunica albuginea of the penis, which may lead to penile curvature and/or erectile dysfunction (ED) [1]. The etiopathogenesis of PD is still less understood and lot more research is still needed in understanding the disease [2].

Acute phase of PD primarily involves conservative management, although few studies report success with collagenase clostridium histolyticum $(\mathrm{CCH})$ injection [3]

Supplementary information The online version of this article (https:// doi.org/10.1038/s41443-020-0325-6) contains supplementary material, which is available to authorized users.

Pramod Krishnappa

Pramod23dr@gmail.com

1 Department of Urology and Robotic Surgery, Hospital Universitario La Zarzuela, Madrid, Spain

2 Department of Urology and Andrology, NU Hospitals, Bengaluru, India

3 Department of Urology, Hospital Puerta De Hierro Majadahonda, Madrid, Spain and/or penile traction therapy (PTT) [4] in acute phase, but the evidence is weak on the same. Chronic phase of PD is the right opportunity for surgical intervention when the penile curvature stabilizes [5].

Penile prosthesis (PP) becomes the mainstay of management in patients with PD with coexistent ED [6]. Residual curvature poses a significant hurdle after PP implantation [7]. In spite of Wilson's intraoperative manual modeling (MM) [8] over a PP, significant penile curvature may persist when the preoperative curvature is beyond $60^{\circ}$ [9]. Additional surgical interventions like grafting may add to the peri-operative morbidity including increased infection rates and higher costs $[10,11]$. Nevertheless, in many series, as many as up to $40 \%$ of patients need surgical correction of the curvature in addition to PP [12].

After intralesional $\mathrm{CCH}$ injection, home modeling (HM) forms an integral aspect of penile rehabilitation program to improve the results [13]. Applying a similar concept [13], Moncada's HM protocol after inflatable penile prosthesis (IPP) implantation helps improve penile curvature thereby reducing the additional surgical maneuvers.

The primary aim of the study was to assess the residual penile curvature postoperatively after 6 months of HM. 


\section{Materials and methods}

A retrospective review of prospectively collected data was performed of all patients diagnosed with PD who underwent IPP implantation between 2008 and 2017. Institutional review board approval was obtained. All patients received AMS 700-CX IPP (Boston Scientific Corp, Marlborough, MA, USA) through a standard peno-scrotal approach. After implantation, the IPP was inflated to maximum and penile curvature was measured using goniometer. All patients underwent subsequent Wilson's MM [8] in the operating room.

If the residual curvature was more than $45^{\circ}$, circumcision and incision-grafting were performed. Rest of the patients with $<45^{\circ}$ residual curvature after MM were instructed to perform HM after 4 weeks from implantation.

The HM protocol consisted of (1) full inflation of the IPP and gently bending (modeling) the penis in the opposite direction of the curvature, (2) each cycle consisted of holding the penis in this stretched position for $30 \mathrm{~s}$, and then subsequently deflating the IPP, (3) such multiple cycles were done in each episode lasting for $20 \mathrm{~min}$, and (4) such three episodes were done every day for 6 months. The HM was first instructed in office by the urologist after 4 weeks of surgery and subsequently done by the patient himself at home.

Demographic and surgical data were collected from the patient medical records. Improvement in penile curvature and patient satisfaction was assessed postoperatively using a non-validated questionnaire (Supplementary Fig. 1). The main outcome measure was the residual curvature at 6 months postoperatively.

\section{Results}

The mean age of the study group was $62.8 \pm 2.7$ years (52-79) (Table 1). A total of 92 patients with PD and coexistent ED received IPP. The mean preoperative penile curvature was $39.4 \pm 5.7^{\circ}(30-60)$. Sixteen $(17.4 \%)$ patients required incision-grafting and the remaining $76(82.6 \%)$ patients followed HM protocol. The mean postoperative residual curvature after $\mathrm{MM}$ was $29.7 \pm 3.2^{\circ}$ (5-50). Sixtyfive $(85.5 \%)$ patients who underwent $\mathrm{HM}$ had $10^{\circ}$ or less residual curvature after 3 months and $72(94.7 \%)$ patients had $10^{\circ}$ or less residual curvature after 6 months (Table 2). Seventy $(92.1 \%)$ patients responded as satisfied or very satisfied on the questionnaire with the outcome after 6 months. The following complications were noted after IPP: hematoma not requiring surgery (six patients), pain lasting $<6$ weeks (four), pump revision for malfunction (one), mechanical failure-tubing leakage (one), and

Table 1 Patient's characteristics.

\begin{tabular}{ll}
\hline Number of patients & 92 \\
Diabetes & 18 \\
Hypertension & 26 \\
Cardiovascular disease & 12 \\
Age (years) & $62.8 \pm 2.7$ \\
\hline
\end{tabular}

Table 2 Results.

\begin{tabular}{lll}
\hline Penile curvature & Preoperative & $\begin{array}{l}\text { After manual } \\
\text { modeling }\end{array}$ \\
& $39.4 \pm 5.7^{\circ}(30-60)$ & $\begin{array}{l}29.7 \pm 3.2^{\circ} \\
(5-50)\end{array}$ \\
Number of patients & $\begin{array}{l}\text { Incision-grafting } \\
16(17.4 \%)\end{array}$ & $\begin{array}{l}\text { Home modeling } \\
76(82.6 \%)\end{array}$ \\
$\begin{array}{l}\text { Number of patients with } \\
\text { residual penile curvature } \\
<10^{\circ}\end{array}$ & At 3 months & At 6 months \\
\hline
\end{tabular}

impending erosion (one). No revision surgery was needed in the first 3 months postoperatively.

\section{Discussion}

The two important goals of surgery in PD are restoration of erectile function and penile curvature correction for a satisfactory sexual intercourse [14]. PP becomes the mainstay of management in patients with PD with coexistent ED [6]. Simultaneously, procedures like plication or incision-grafting are usually done if residual curvature persists beyond $30^{\circ}$ even after MM [5].

The additional surgical maneuvers needed after IPP implantation in PD ranges between 19 and $42 \%$ and may be associated with complications [7, 12, 15-17]. Terrier et al. pointed out that the penile sensory changes range from 2 to $21 \%$ after incision-grafting and it may take up to 1 year for the resolution of complete loss of sensation [18]. Graft herniation, penile sensory changes, glans edema, recurrence of curvature due to graft contraction, and graft infection rates vary significantly depending on the type of graft used [15-17].

American Urological Association guidelines on PD recommend the use of only IPP and not malleable PP in PD; however, this is only an "Expert Opinion" [19]. Our study included the use of IPP only. Although MM can be done over a malleable PP, IPP is still the most preferred option for MM. Garaffa et al. reported that a three-piece IPP provides better strength than the malleable for MM. In his study group of 209 patients, adequate straightening was 
achieved in $89.6 \%$ of cases with a three-piece IPP and $53.8 \%$ with a malleable PP [12].

There are few studies [20-22] highlighting the role of IPP acting as a tissue expander by stretching the corpora over few months and all these studies have different postoperative IPP cycling protocols stating improvements in penile length. None of these studies [20-22] commented on improvements in penile curvature with cycling of IPP, probably due to the correction of curvature by additional surgical maneuvers.

Wilson et al. [20] proposed a protocol which achieved girth and length enhancement by $2-4 \mathrm{~cm}$ in patients with previous infection, but only girth enhancement in patients with prior priapism. The protocol involved inflating the IPP for up to $3 \mathrm{~h}$ daily over a period of 8-12 months. In 40 patients, Henry et al. [21] followed a protocol which involved daily inflation of the IPP from 6 weeks to 1 year with a compulsory inflation of $1-2 \mathrm{~h}$ in last 6 months. With this, they noted improvements in penile length, penile circumference, girth and satisfaction rates at 12 months. Penile length increased by $1.14,0.99$, and $1.04 \mathrm{~cm}$ for erect, flaccid, and stretched penis, respectively, at 12 months. Chung et al. [22] accessed the American Medical Systems and Coloplast Patient Information Form databases of 2749 patients and reported that $60 \%$ of patients increased $>0.5 \mathrm{~cm}$ and $40 \%$ increased $\geq 1 \mathrm{~cm}$ in IPP cylinder length at $\geq 2$ years. The authors highlighted the possible role of IPP as a tissue expander to increase internal penile length.

PTT has gained popularity in recent years, it being a nonsurgical modality to treat PD. The clinical studies reporting the efficacy of PTT have small study groups and lack randomization and patient compliance [23, 24]. The European Association of Urology 2019 guidelines confer a "weak" recommendation for the use of PTT to reduce penile deformity and increase the penile length [25]. Mechanotransduction is a process that converts mechanical stimuli to cellular biochemical responses.

With the use of mechanical traction and tissue expansion therapy, alteration of connective tissue by cellular proliferation and expansion of the extracellular matrix have been demonstrated [26]. Having borrowed the concept of mechanotransduction from bone remodeling [27] and Dupuytren's contracture studies [28], Chung et al. [29] performed the first in vitro experimental analysis to study the efficacy of tissue traction therapy in PD. Chung et al. documented significant alterations in the ultrastructure of connective tissue with increased collagenase activity and decreased collagen-elastin staining. We assume that IPP does the role of PTT as the postoperative IPP cycling causes repeated stretching of tunica albuginea which results in mild-moderate correction of penile curvature, thereby avoiding additional surgical maneuvers. The strong build quality of the IPP cylinders can withstand the pressures during HM and MM. The cylinder tubings are clamped during intraoperative $\mathrm{MM}$, which of course is not done during HM.

The IMPRESS trial [13] mentioned about the penile plaque modeling done by the physician during the first visit after two $\mathrm{CCH}$ injections and subsequent HM was done by the patient himself. Ziegelmann et al. [30] slightly modified this protocol and instructed his patients to perform the HM themselves (rather than the physician) beginning on the first day of the CCH injection [21]. Like in IMPRESS trial [13], in our study, the first modeling session was done by the physician in the clinic when the patient came for the first postoperative visit at 4 weeks and subsequent ones were done by the patient himself at home. We noted that no cases of tunical rupture due to HM, and it was well accepted by majority of patients.

HM after IPP has not been documented in the literature for residual curvature correction, although studies [20-22] have reported on penile length and girth increment after IPP. This would be the first study to highlight the importance of HM after IPP for residual curvature correction even up to $45^{\circ}$. Limitations of this study include: (a) use of a nonvalidated questionnaire to assess satisfaction, (b) recall bias as 6 months is a longer time for recall period in a questionnaire-based assessment, (c) lack of power analysis, and (d) lack of a control group.

\section{Conclusion}

This is a pilot study reporting the effectiveness of HM and is a viable option in preventing adjunctive surgical maneuvers after IPP implantation even up to residual curvature of $45^{\circ}$. The HM protocol described in our study is patient friendly, easily reproducible, and not cumbersome. Six months of HM gives satisfactory results with no adverse effects.

Author contributions All authors have: conceived and/or designed the work that led to the submission, acquired data, and/or played an important role in interpreting the results; drafted or revised the paper; approved the final version; agreed to be accountable for all aspects of the work in ensuring that questions related to the accuracy or integrity of any part of the work are appropriately investigated and resolved.

\section{Compliance with ethical standards}

Conflict of interest The authors declare that they have no conflict of interest.

Publisher's note Springer Nature remains neutral with regard to jurisdictional claims in published maps and institutional affiliations. 


\section{References}

1. Hellstrom W. History, epidemiology, and clinical presentation of Peyronie's disease. Int J Impot Res. 2003;15 Suppl 5:S91-2.

2. Sharma KL, Alom M, Trost L. The etiology of Peyronie's disease: pathogenesis and genetic contributions. Sex Med Rev. 2020;8:314-23.

3. El-Khatib FM, Towe M, Yafi FA. Management of Peyronie's disease with collagenase clostridium histolyticum in the acute phase. World J Urol. 2020;38:299-304.

4. Martínez-Salamanca JI, Egui A, Moncada I, Minaya J, Ballesteros CM, Del Portillo L. Acute phase peyronie's disease management with traction device: a nonrandomized prospective controlled trial with ultrasound correlation. J Sex Med. 2014;11:506-15.

5. Anaissie J, Yafi FA. A review of surgical strategies for penile prosthesis implantation in patients with Peyronie's disease. Transl Androl Urol. 2016;5:342-50.

6. Krishnappa P, Fernandez-Pascual E, Carballido J, Moncada I, Lledo-Garcia E, Martinez-Salamanca JI. Surgical management of Peyronie's disease with co-existent erectile dysfunction. Sex Med. 2019;7:361e370.

7. Mulhall J, Ahmed A, Anderson M. Penile prosthetic surgery for Peyronie's disease: defining the need for intraoperative adjuvant maneuvers. J Sex Med. 2004;1:318-21.

8. Wilson SK, Delk JR 2nd. A new treatment for Peyronie's disease: modeling the penis over an inflatable penile prosthesis. J Urol. 1994;152:1121-3.

9. Levine LA, Burnett AL. Standard operating procedures for Peyronie's disease. J Sex Med. 2013;10:230-44.

10. Hatzichristodoulou G, Tsambarlis $\mathrm{P}$, Kübler $\mathrm{H}$, Levine LA. Peyronie's graft surgery-tips and tricks from the masters in andrologic surgery. Transl Androl Urol. 2017;6:645-56.

11. Chung E. Penile reconstructive surgery in Peyronie disease: challenges in restoring normal penis size, shape, and function. World J Mens Health. 2020;38:1-8.

12. Garaffa G, Minervini A, Christopher NA, Minhas S, Ralph DJ. The management of residual curvature after penile prosthesis implantation in men with Peyronie's disease. BJU Int. 2011;108:1152-6.

13. Gelbard M, Goldstein I, Hellstrom WJ, McMahon CG, Smith T, Tursi J, et al. Clinical efficacy, safety and tolerability of collagenase clostridium histolyticum for the treatment of Peyronie disease in 2 large double-blind, randomized, placebo controlled phase 3 studies. J Urol. 2013;190:199-207.

14. Garaffa G, Kuehhas FE, De Luca F, Ralph DJ. Long-term results of reconstructive surgery for Peyronie's disease. Sex Med Rev. 2015;3:113-21.

15. Hatzichristodoulou G, Osmonov D, Kübler H, Hellstrom WJG, Yafi FA. Contemporary review of grafting techniques for the surgical treatment of Peyronie's disease. Sex Med Rev. 2017;5:544-52.
16. Rice PG, Somani BK, Rees RW. Twenty years of plaque incision and grafting for Peyronie's disease: a review of literature. Sex Med. 2019;7:115-28.

17. Garcia-Gomez B, Ralph D, Levine L, Moncada-Iribarren I, Djinovic R, Albersen M, et al. Grafts for Peyronie's disease: a comprehensive review. Andrology. 2018;6:117-26.

18. Terrier JE, Tal R, Nelson CJ, Mulhall JP. Penile sensory changes after plaque incision and grafting surgery for Peyronie's disease. J Sex Med. 2018;15:1491-7.

19. Nehra A, Alterowitz R, Culkin DJ, Faraday MM, Hakim LS, Heidelbaugh JJ, et al. Peyronie's disease: AUA guideline. J Urol. 2015;194:745-53.

20. Wilson SK, Delk JR, Mulcahy JJ, Cleves M, Salem EA. Upsizing of inflatable penile implant cylinders in patients with corporal fibrosis. J Sex Med. 2006;3:736-42.

21. Henry GD, Carrion R, Jennermann C, Wang R. Prospective evaluation of postoperative penile rehabilitation: penile length/ girth maintenance 1 year following Coloplast Titan inflatable penile prosthesis. J Sex Med. 2015;12:1298-304.

22. Chung PH, Siegel JA, Tausch TJ, Klein AK, Scott JM, Morey AF. Inflatable penile prosthesis as tissue expander: what is the evidence? Int Braz J Urol. 2017;43:911-6.

23. Valenzuela R, Ziegelmann M, Tokar S, Hillelsohn J. The use of penile traction therapy in the management of Peyronie's disease: current evidence and future prospects. Ther Adv Urol. 2019;11:1756287219838139. https://doi.org/10.1177/175628721 9838139.

24. Moncada I, Krishnappa P, Romero J, Torremade J, Fraile A, Martinez-Salamanca JI, et al. Penile traction therapy with the new device 'Penimaster PRO' is effective and safe in the stable phase of Peyronie's disease: a controlled multicentre study. BJU Int. 2019;123:694-702.

25. Hatzimouratidis K, Giuliano F, Moncada I, Muneer A, Salonia A, Verze P. EAU guidelines: male sexual dysfunction [Internet]. Uroweb. http://uroweb.org/guideline/male-sexual-dysfunction/. Accessed 1 Oct 2019

26. Alenghat FJ, Ingber DE. Mechanotransduction: all signals point to cytoskeleton, matrix, and integrins. Sci STKE. 2002;2002:pe6.

27. Ilizarov GA, Soǐbel'man LM. Clinical and experimental data on bloodless lengthening of lower extremities. Eksp Khir Anesteziol. 1969;14:27-32.

28. Alman BA, Greel DA, Ruby LK, Goldberg MJ, Wolfe HJ. Regulation of proliferation and platelet-derived growth factor expression in palmar fibromatosis (Dupuytren contracture) by mechanical strain. J Orthop Res. 1996;14:722-8.

29. Chung E, De Young L, Brock GB. Penile traction and Peyronie's disease: in-vitro analysis of the efficacy of traction on cellular changes in Peyronie's plaque in a strain culture system. J Sex Med. 2012,9 Suppl 2:130.

30. Ziegelmann MJ, Viers BR, McAlvany KL, Bailey GC, Savage JB, Trost LW. Restoration of penile function and patient satisfaction with intralesional collagenase clostridium histolyticum injection for Peyronie's disease. J Urol. 2016;195:1051-6. 
Journal : 41443

Article : 325

\section{SPRINGER NATURE}

\section{Author Query Form}

\section{Please ensure you fill out your response to the queries raised below and return this form along with your corrections}

\section{Dear Author}

During the process of typesetting your article, the following queries have arisen. Please check your typeset proof carefully against the queries listed below and mark the necessary changes either directly on the proof/online grid or in the 'Author's response' area provided below

\begin{tabular}{|c|c|c|}
\hline Queries & Details Required & Author's Response \\
\hline AQ1 & $\begin{array}{l}\text { Since the references were not cited in numerical order, they have been renumbered in the order of } \\
\text { appearance. Please check. }\end{array}$ & \\
\hline AQ2 & $\begin{array}{l}\text { Please check your article carefully, coordinate with any co-authors and enter all final edits clearly } \\
\text { in the eproof, remembering to save frequently. Once corrections are submitted, we cannot } \\
\text { routinely make further changes to the article. }\end{array}$ & \\
\hline AQ3 & $\begin{array}{l}\text { Note that the eproof should be amended in only one browser window at any one time; otherwise } \\
\text { changes will be overwritten. }\end{array}$ & \\
\hline AQ4 & $\begin{array}{l}\text { Author surnames have been highlighted. Please check these carefully and adjust if the first name } \\
\text { or surname is marked up incorrectly. Note that changes here will affect indexing of your article in } \\
\text { public repositories such as PubMed. Also, carefully check the spelling and numbering of all } \\
\text { author names and affiliations, and the corresponding email address(es). }\end{array}$ & \\
\hline AQ5 & $\begin{array}{l}\text { You cannot alter accepted Supplementary Information files except for critical changes to scientific } \\
\text { content. If you do resupply any files, please also provide a brief (but complete) list of changes. If } \\
\text { these are not considered scientific changes, any altered Supplementary files will not be used, only } \\
\text { the originally accepted version will be published. }\end{array}$ & \\
\hline AQ6 & Please confirm or correct the city name inserted in affiliation 2 . & \\
\hline AQ7 & $\begin{array}{l}\text { Original reference [15] is a duplicate of [5] and hence the repeated version has been deleted. } \\
\text { Please check. }\end{array}$ & \\
\hline AQ8 & $\begin{array}{l}\text { Please confirm that the edits to the sentences "The clinical studies reporting the efficacy..." and } \\
\text { "We noted that no cases of..."preserve the originally intended meaning. }\end{array}$ & \\
\hline
\end{tabular}

